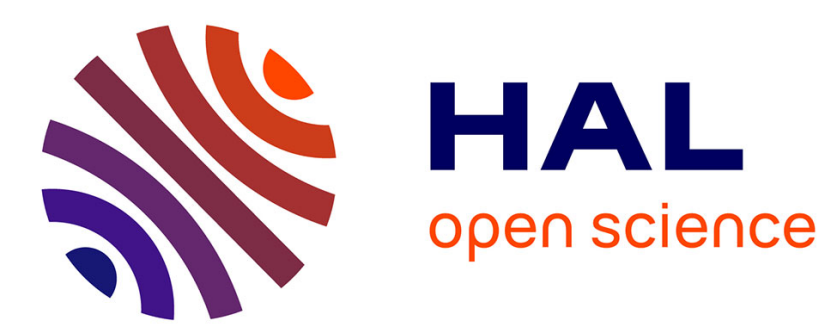

\title{
Problem-oriented drug information: physicians' expectations and impact on clinical practice
}

\author{
U. Hedegaard, P. Damkier
}

\section{To cite this version:}

U. Hedegaard, P. Damkier. Problem-oriented drug information: physicians' expectations and impact on clinical practice. European Journal of Clinical Pharmacology, 2009, 65 (5), pp.515-522. 10.1007/s00228-008-0604-5 . hal-00534938

\section{HAL Id: hal-00534938 \\ https://hal.science/hal-00534938}

Submitted on 11 Nov 2010

HAL is a multi-disciplinary open access archive for the deposit and dissemination of scientific research documents, whether they are published or not. The documents may come from teaching and research institutions in France or abroad, or from public or private research centers.
L'archive ouverte pluridisciplinaire HAL, est destinée au dépôt et à la diffusion de documents scientifiques de niveau recherche, publiés ou non, émanant des établissements d'enseignement et de recherche français ou étrangers, des laboratoires publics ou privés. 


\title{
Problem-oriented drug information: physicians' expectations and impact on clinical practice
}

\author{
U. Hedegaard • P. Damkier
}

Received: 23 September 2008 / Accepted: 5 December 2008 /Published online: 10 January 2009

(C) Springer-Verlag 2009

\begin{abstract}
Purpose Problem-oriented drug information (POD) is a service in which health professionals provide evidencebased answers to clinical questions posed by physicians. The objective of this study was to evaluate the user satisfaction and clinical impact of POD, to investigate predictors for use and to examine the kind of sources physicians search before applying for POD.

Methods To evaluate POD, a questionnaire was distributed with problem-oriented answers sent from a drug information centre to physicians during the period of April 2006 to March 2007.

Results Of 197 questionnaires, 183 (93\%) were returned. The information from the POD service was highly valued by the physicians, and $90 \%$ of the answers led to reported impact on clinical practice in the specific clinical situation. Furthermore, $74 \%$ of the answers were intended to be used in a wider context either for future patients $(67 \%)$ or for dissemination to colleagues $(51 \%)$. Secondary-care physicians more often than general practitioners (GPs) used the information for dissemination to colleagues ( 63 vs. $39 \%, P=0.0008$ ), while GPs more often used the answer to support patient information ( 88 vs. $70 \%, P=0.0029$ ). The most prominent motive for applying for POD was a request for evidencebased information (78\%), and the service was used to
\end{abstract}

\footnotetext{
U. Hedegaard · P. Damkier

Department of Biochemistry, Pharmacology and Genetics,

Odense University Hospital,

Odense, Denmark

U. Hedegaard $(\triangle)$

Institute of Public Health, Clinical Pharmacology,

University of Southern Denmark,

Winsløwparken 19, 2nd,

5000 Odense, Denmark

e-mail: uhedegaard@health.sdu.dk
}

overcome barriers to practicing evidence-based medicine such as lack of time (36\%), skills for searching (26\%), and appraising the literature (13\%). Before inquiring, $74 \%$ of the physicians had tried other information sources; the most frequent sources used were a drug reference (68\%) and consulting a colleague (24\%). Secondary-care physicians reported fewer barriers than GPs when seeking information, and secondary-care physicians searched other sources more often than GPs before contacting the service ( 81 vs. $67 \%, P=0.031$ ).

Conclusion POD represents a useful source for acquiring evidence-based drug information by physicians. POD is highly valued by the users. It was reported to have an impact on clinical practice for the specific patient but is also intended to be used in a wider context for future patients or for dissemination to colleagues. GPs' and secondary-care physicians' use of POD differs with GPs having more focus on patient information and secondary-care physicians having more focus on dissemination of the information to colleagues.

Keywords Drug information services · Evidence-based medicine $\cdot$ Physicians · Information storage and retrieval . Information dissemination $\cdot$ Behaviour

\section{Introduction}

Questions about patient management arise in daily practice, with 0.16 to 1.27 questions per patient depending on the methodology used and the clinical setting [1]. A great many of the questions concern pharmacotherapy. About $60 \%$ of the answers are simple, such as the dose of a drug, and can easily be located by looking in textbooks or medication databases [1]. Other questions are more complex and a large portion remain unanswered although in many cases an answer exists in the literature that would have changed the physician's decision $[2,3]$. 
Physicians are urged to practice evidence-based medicine when facing questions about patient care. However, in a busy practice this may be difficult, though most physicians are enthusiastic about evidence-based medicine $[4,5]$. Despite the increased access to updated primary evidence (e.g. PubMed) and databases of pre-appraised evidence-based medicine (EBM), the traditional methods of seeking information such as consulting a colleague or use of paper sources still prevail amongst qualified medical staff in the clinical setting [1, 3, 6]. Electronic EBM sources seem rarely to be the primary resource of information [6, 7], even though studies show that a substantial number of clinicians' questions can be answered by pre-appraised EBM sources [8-10].

Numerous explanations account for the unanswered questions and the non-compliance to evidence-based practice. The most prominent barrier is the lack of time to find the information. Other major barriers include difficulty formulating an appropriate search question, limited search skills and familiarity with evidence-based resources, limited access to EBM sources and the Web in clinics, uncertainty as to whether the relevant information has been found, and lack of skills to appraise the literature and transfer the many pieces of evidence into a clinically useful approach $[1,3,4,11]$.

Problem-oriented drug information (POD) may be a method to overcome some of the physician's barriers to practicing evidence-based medicine. POD is an answering service for the physician where the information is designed to include a discussion of the specific patient problem rather than to purely retrieve and forward pertinent literature. The information is typically provided by clinical pharmacologists or pharmacists with expertise in literature retrieval and appraisal [12-15], and the working method has much in common with the concept of EBM. A few studies have shown that POD has an impact on clinical practice [15-17]. Since then, the access to userfriendly electronic EBM resources has increased and physicians' attitudes towards POD may have changed. The motives that trigger the use of POD have not been investigated in depth and could be helpful for characterisation of the need and eligibility of POD as a method to change clinical practice. The objective of this study was to examine the user satisfaction and clinical impact of POD, to investigate predictors for use and to examine the information sources that physicians have tried before contacting the service. Further, we discuss whether POD is a method to improve physicians' practice towards evidence-based therapy.

\section{Materials and methods}

\section{Drug Information Centre}

The Drug Information Centre is a regional centre that serves the southern region of Denmark. It is organised within a clinical pharmacology unit at the Department of Biochemistry, Pharmacology and Genetics, Odense University Hospital. The aim is to offer POD to physicians and other health professionals and to promote rational pharmacotherapy in clinical practice. The staff consists of two clinical pharmacologists and two clinical pharmacists. In addition, clinical pharmacology trainees, presently two, participate in running the service.

To ensure high quality answers, the work is done in a strictly standardised way outlined in written instructions. To get access to our service, it is a prerequisite that the answer is not available in The Danish National Drug Reference, Medicin.dk. The service is free of cost for the users. In order to find up-to-date and evidence-based medical information, a comprehensive literature search is performed using bibliographic databases, pre-appraised EBM sources, drug information databases, medical websites and the centre's own library consisting of textbooks and journals. The answer is provided within a timeframe defined by the enquirer. A preliminary telephone answer is provided when needed. The answer is prepared by clinical pharmacists or clinical pharmacology trainees under supervision of a clinical pharmacologist. The written answer goes briefly through the literature and ends with a conclusion consisting of a summary of the evidence and recommendations for the specific clinical situation, if appropiate. All answers are documented with references. Except for questions where a previous answer can be used, all answers are internally reviewed and approved at a weekly staff meeting before being sent to the enquirer.

All questions and answers are documented in a web-based question-answer database available to other clinical pharmacology units in Denmark. All answers are in English as the majority of the answers are published in the international online question-answer database, Drugline. From these databases, it is easy to retrieve previous answers from our own or other drug information centres, and therefore the answers can easily be updated and unnecessary repetition is avoided.

\section{Questionnaire}

From April 2006 to March 2007, a questionnaire was mailed to all physicians who received a written problem-oriented answer related to a specific patient. Answers to questions of a general or technical nature or answers to health professionals other than physicians were excluded from the study. To maximise response rate, a reminder and a new questionnaire were mailed 3 weeks later to non-responders. The questionnaire was coded with the number of the corresponding query to the Drug Information Centre. In this way the response to the questionnaire could be linked to the characteristics of the enquirer documented in the question-answer database.

As there were no published standardised instruments, a new questionnaire was developed on the basis of items 
identified in qualitative interviews with eight users of the Drug Information Centre. The questionnaire was pre-tested with ten previous users before the study.

The questionnaire contained eight questions. Five questions were related to the user satisfaction with the answer. The physicians were asked about the level of satisfaction with the answer in general as well as with the extent, answer time and usefulness of the answer. These four questions were to be prioritised on a five-point scale ranging from completely satisfactory to completely dissatisfactory. Finally, the physicians were asked whether they would use the service again, and here it was possible to answer yes, no or perhaps.

To examine the physician's motive for applying to POD, the physicians were asked why they contacted the service. Further, they were asked which drug information sources they had sought before requiring the service. Finally, to assess the impact, the physicians were asked how the answer was used. Multiple replies were allowed for these three questions in preprinted categories together with an option to answer "other" and specify, if appropriate.

\section{Data analysis}

Data are presented as actual numbers and percentages. Inferential statistics are two-tailed $P$ values associated with the z-ratio for independent proportions. As this study was exploratory and descriptive in nature, no corrections for multiple testing were applied. Statistical analysis was performed using an online calculator (http://faculty.vassar. edu/lowry/VassarStats.html, accessed August 19, 2008).

\section{Results}

Physicians

A questionnaire accompanied 197 answers sent to physicians. The total number of answers during the study period was 226 . Among these, 29 were excluded from the study because they were answers to health professionals other than physicians or answers to questions of a general nature. Of the 197 questionnaires mailed out, 183 (93\%) were returned. Among the responders, $97(53 \%)$ worked as general practitioners (GPs) in primary care. Of the $86(47 \%)$ physicians working in secondary care, $80(93 \%)$ worked at hospitals and 6 physicians worked as medical specialists outside hospitals. During the 1-year study period, 3 physicians contacted the information service three times, 20 (13\%) twice and 134 (85\%) physicians used the service only once. Of the 183 responders, 97 (53\%) were female. There were no differences between responders and non-responders regarding the abovementioned characteristics.

\section{Questions}

Thirty-one percent of the questions dealt with pregnancy, 24\% with drug interactions, $22 \%$ with adverse reactions, $10 \%$ with choice of treatment, $6 \%$ with lactation and $7 \%$ with miscellaneous issues. A preliminary telephone or e-mail answer was given for 117 (64\%) of the questions with a median answer time of 1 day (range $0-43,95 \%$ percentile: 19 days). The median answer time of the written answer was 27 days (range 0-284, 95\% percentile: 104 days).

\section{Impact of the answer}

Ninety-seven percent of physicians found that the answer was useful in the clinical situation, either completely useful $(83 \%)$ or partially useful $(14 \%)$. The use of the answer was classified into two main categories: use related to the specific patient or to a broader application, and the results are shown in Table 1.

User satisfaction with the answer

In all, 176 (96\%) physicians reported willingness to use POD again. The assessment of the four other satisfaction parameters related to the answer is shown in Table 2. There

Table 1 Physicians' assessment of the impact of the written answer from a drug information centre

\begin{tabular}{|c|c|c|c|c|}
\hline Impact & GP $(n=97)$ & $\mathrm{SC}(n=86)$ & Total $(n=183)$ & $P$ value \\
\hline Application related to a specific patient & $91(94 \%)$ & $73(85 \%)$ & $164(90 \%)$ & 0.048 \\
\hline For patient information & $85(88 \%)$ & $60(70 \%)$ & $145(79 \%)$ & 0.0029 \\
\hline Change in therapy & $39(40 \%)$ & $43(50 \%)$ & $82(45 \%)$ & 0.18 \\
\hline Broader application & $68(70 \%)$ & $68(79 \%)$ & $136(74 \%)$ & 0.97 \\
\hline Dissemination to colleagues & $38(39 \%)$ & $55(63 \%)$ & $93(51 \%)$ & 0.0008 \\
\hline For future patients & $64(66 \%)$ & $59(68 \%)$ & $123(67 \%)$ & 0.71 \\
\hline \multicolumn{5}{|l|}{ Other } \\
\hline Personal interest (nice to know) & $42(43 \%)$ & $36(42 \%)$ & $78(43 \%)$ & 0.84 \\
\hline Not used & $1(1 \%)$ & 0 & $1(0.5 \%)$ & ND \\
\hline
\end{tabular}

$G P$ General practitioner, $S C$ secondary-care physician, $N D$ not determined 
Table 2 Physicians' satisfaction with the written answer from a drug information centre

\begin{tabular}{lllll}
\hline $\begin{array}{l}\text { Level of } \\
\text { satisfaction }\end{array}$ & $\begin{array}{l}\text { The written answer } \\
(n=183)\end{array}$ & $\begin{array}{l}\text { Answer time of the } \\
\text { written answer }(n=181)\end{array}$ & $\begin{array}{l}\text { Extent of the written } \\
\text { answer }(n=183)\end{array}$ & $\begin{array}{l}\text { Usefulness of written/ } \\
\text { preliminary answer }(n=183)\end{array}$ \\
\hline Completely satisfactory & $170(92.9 \%)$ & $121(66.9 \%)$ & $145(79.2 \%)$ & $152(83.1 \%)$ \\
Partially satisfactory & $12(6.6 \%)$ & $34(18.8 \%)$ & $31(16.9 \%)$ & $25(13.7 \%)$ \\
Neither/Nor & $1(0.5 \%)$ & $12(6.6 \%)$ & $1(0.5 \%)$ & $5(2.7 \%)$ \\
Partially dissatisfactory & 0 & $10(5.5 \%)$ & $6(3.3 \%)$ & $0.5 \%)$ \\
Completely dissatisfactory & 0 & $4(2.2 \%)$ & 0 & 0 \\
\hline
\end{tabular}

was no difference between GPs and secondary-care physicians with regard to the assessment of these four parameters (not shown). The answer time was the parameter where most dissatisfaction was observed. There were 155 (86\%) physicians who found the written answer time completely or partially satisfactory. Among these physicians, the median answer time was 25 days (range 0-132 days) and 101 (67\%) had received a preliminary answer. Among the 26 answers (14\%) whose answer time was not described as satisfactory, the median answer time was 56 days, and among these 15 $(58 \%)$ had received a preliminary answer. For answers received within 25 days $(n=83)$ and 56 days $(n=146)$, the number of physicians who were completely or partially satisfied amounted to $79(95 \%)$ and 133 (91\%), respectively.

Motive for applying for problem-oriented drug information

The motives for inquiring were classified into three main categories: need for high quality information, patient- related motives and motives related to information-seeking barriers (see Table 3).

Information sources searched before inquiring

The different resources searched before inquiring were classified into two categories: written information and personal communication with health professionals (see Table 4).

\section{Discussion}

Impact of the answer

Our study confirms that POD is a valuable method for providing useful, high quality information to physicians within the management of patient care. We found that $90 \%$ of the answers were used in the clinical situation, either for patient information $(79 \%)$ and/or for change of therapy

Table 3 Physicians' motives for applying for problem-oriented drug information from a drug information centre

\begin{tabular}{llll}
\hline Motive & GP $(n=97)$ & SC $(n=85)$ & Total $(n=182)$ \\
\hline Need for high-quality information & $86(89 \%)$ & $73(86 \%)$ & $159(87 \%)$ \\
Need for evidence-based information & $74(76 \%)$ & $68(80 \%)$ & $142(78 \%)$ \\
Need for neutral information & $36(37 \%)$ & $27(32 \%)$ & $63(34 \%)$ \\
Need for written information & $18(19 \%)$ & $19(22 \%)$ & $37(20 \%)$ \\
Divergent information from other sources & $21(22 \%)$ & $15(18 \%)$ & $36(20 \%)$ \\
Other & $1(1 \%)$ & 0.58 & $1(0.5 \%)$ \\
Need for patient-related information & $74(76 \%)$ & $62(73 \%)$ & $136(75 \%)$ \\
Patient's safety & $56(58 \%)$ & $55(65 \%)$ & $111(61 \%)$ \\
For future patients & $42(43 \%)$ & $46(54 \%)$ & $88(48 \%)$ \\
Need for decision support & $45(46 \%)$ & $34(40 \%)$ & $79(43 \%)$ \\
Support for patient information & $37(38 \%)$ & $20(24 \%)$ & $57(31 \%)$ \\
Information-seeking barriers & $53(55 \%)$ & $40(47 \%)$ & $93(51 \%)$ \\
Lack of time to search for the information & $37(38 \%)$ & $28(33 \%)$ & $63(36 \%)$ \\
Lack of skills in searching the literature & $32(33 \%)$ & $15(18 \%)$ & $47(26 \%)$ \\
Lack of skills in appraising the literature & $17(18 \%)$ & $6(7 \%)$ & $23(13 \%)$ \\
No access to information sources & $2(2 \%)$ & $4(5 \%)$ & 6.53 \\
Other & & & 0.50 \\
Personal interest (nice to know) & $20(21 \%)$ & $26(31 \%)$ & 0.34 \\
Dissemination to colleagues & $17(18 \%)$ & $27(32 \%)$ & 0.39 \\
Supplementary training/develop competence & $13(13 \%)$ & $21(25 \%)$ & 0.31 \\
Own safety (patient complaints) & $15(15 \%)$ & $10(12 \%)$ & 0.46 \\
\hline
\end{tabular}

$G P$ General practitioner, $S C$ secondary-care physician, $N D$ not determined 
Table 4 Information sources physicians searched before contacting a drug information centre

\begin{tabular}{|c|c|c|c|c|}
\hline Information searched & GP $(n=97)$ & $\mathrm{SC}(n=85)$ & Total $(n=182)$ & $P$ value \\
\hline Searched other sources & $65(67 \%)$ & $69(81 \%)$ & $134(74 \%)$ & 0.031 \\
\hline Searched more than one source & $40(41 \%)$ & $50(59 \%)$ & $90(49 \%)$ & 0.018 \\
\hline None & $32(33 \%)$ & $16(19 \%)$ & $48(26 \%)$ & 0.031 \\
\hline Written information & $63(65 \%)$ & $66(78 \%)$ & $129(71 \%)$ & 0.060 \\
\hline Drug Reference (Medicin.dk) & $61(63 \%)$ & $63(74 \%)$ & $124(68 \%)$ & 0.10 \\
\hline Medical/pharmaceutical websites & $14(14 \%)$ & $24(28 \%)$ & $38(21 \%)$ & 0.022 \\
\hline Scientific papers & $7(7 \%)$ & $21(25 \%)$ & $28(15 \%)$ & 0.0011 \\
\hline Personal communication & $31(32 \%)$ & $34(40 \%)$ & $65(36 \%)$ & 0.26 \\
\hline Colleague & $20(21 \%)$ & $24(28 \%)$ & $44(24 \%)$ & 0.23 \\
\hline Consultant & $11(11 \%)$ & $16(19 \%)$ & $37(15 \%)$ & 0.16 \\
\hline Manufacturer & $2(2 \%)$ & $11(13 \%)$ & $13(7 \%)$ & ND \\
\hline Community pharmacy & $3(3 \%)$ & $1(1 \%)$ & $4(2 \%)$ & $\mathrm{ND}$ \\
\hline Hospital pharmacy & $1(1 \%)$ & 0 & $1(0.5 \%)$ & ND \\
\hline
\end{tabular}

$G P$ General practitioner, $S C$ secondary-care physician, $N D$ not determined

(45\%). Two other Scandinavian drug information centres, with similar organisation, activity and working procedures found an impact on clinical practice in 61 and $67 \%$ of answers, respectively $[15,16]$. The impact measure in our study differed from the two other studies in two ways. In contrast to our work, the Norwegian study included change in routine and control of ongoing pharmacotherapy as impacts [15], and in the Swedish study, answers that supported continuation of current therapy were included [16]. A reason for the higher impact may be that our questionnaire had fixed categories (patient information and dissemination to colleagues), while in the two other studies, change in clinical practice was to be described in free text. It is possible that the responders in the other studies did not assess patient information as a change in clinical practice.

Evidence-based answering services for GPs, where clinical questions in general and not only limited to pharmacotherapy are being answered by clinical librarians or GPs have also evaluated the impact on the patient [18-21]. All these studies promoted the usefulness of an evidence-based answering service, and 20$55 \%$ of the GPs reported that the given answers had an effect on their patients. POD is a more specialised service employing pharmacological specialists, which may contribute to the higher impact of POD compared to a general answering service.

In addition to applications to the specific patient, our study suggests that POD may affect the clinical practice in a broader sense. Two-thirds of the physicians stated that they intended to use the information for future patients, which is similar to what Lyrvall found [16]. Half of the physicians would use it for dissemination to colleagues, which is similar to the findings by Pomp et al. [15].

User satisfaction with the answer

The information was highly valued by the physicians in our study. More than $90 \%$ of the physicians found that the given information was of satisfactory quality in general and specifically with regard to the usefulness and the extent of the written answer, which is similar to the results from the two Scandinavian drug information centres $[15,16]$. Nearly all physicians stated that they would use the service again, which we consider to be an indirect indication of satisfaction with the service.

In addition to being reliable and useful, information sources should be readily available and quick to use to be rated useful [6]. In our study, the answer time of the written answer was the most criticised parameter, supporting that the rapidity of the answer is important for the usefulness of the answer. Fourteen percent of the physicians found that the answer time was not satisfactory, which is similar to the Swedish study where $13 \%$ stated that the answer was not fast enough. A major proportion of the clinical questions received by evidence-based answering service are complex and make searching primary literature necessary [20, 21]. Rigorous critical appraisal of primary literature is a timeconsuming process requiring access to full text articles and frequent requests for interlibrary loans. This poses a limit to how fast a written answer can be. The median answer time in our study was in the same order of magnitude as the Swedish study (25 vs. 20 days) [16]. In the Norwegian study, nearly all participants were satisfied with the answer time but the exact answer time was not mentioned. We analysed the answer time of the responders who were dissatisfied, and it seems that an answer time of less than 25 days may ensure a high user satisfaction with the answers. It should be noted that a majority of the responders who were dissatisfied had received a preliminary answer within a few days.

Motives for applying for problem-oriented drug information

The most prominent reasons for requesting POD were a need for evidence-based information and decision support 
on behalf of the safety of a specific patient or future patients. The results support that EBM is a well-known concept and physicians generally have a positive attitude towards it $[4,5]$. Our study confirms that time constraints, lack of skills in searching and appraising the literature and limited access to EBM sources are considerable barriers to answering clinical drug questions [1, 3, 4, 11]. A study among Danish hospital physicians found that most of them seemed to lack knowledge of the most basic aspects of evidence-based medicine, and this may represent another substantial barrier to implementing EBM into clinical practice [7]. Studies on the effect of training in EBM and searching the literature show contradictory results $[4,22-$ 24] and GPs seem to prefer predigested, evidence-based information over developing the skills to produce the information themselves [5]. Even though the physicians have access to search in pre-appraised sources, a major portion of complex questions require an additional search in primary literature $[9,10]$, require access to a diverse set of sources and typically take hours to be answered [9]. In this situation, it seems obvious to seek POD to overcome time constraints, lack of access and lack of skills in searching and appraising the literature.

\section{Sources searched before inquiring}

The National Drug Reference, Medicin.dk, was the major text source for information, followed by communication with human sources, in particular colleagues, while electronic text sources were a minor source. The same ranking of information sources was found in systematic reviews of physicians' information-seeking behaviour $[1,3,6]$, and this pattern is also consistent with a study showing that Danish hospital physicians most often consulted textbooks, colleagues and scientific journals whereas evidence-based electronic sources were least consulted [7]. We did not ask whether the websites used were EBM sources, but comments by the responders show that the Internet use included EBM sources (e.g. PubMed). The exact frequency of use of EBM sources can not be estimated from our results, but Danish hospital physicians have reported that $44 \%$ used PubMed often while other EBM sources were seldomly used [7]. Among Danish GPs, 44\% used information found in EBM sources in clinical practice (frequency of use not stated) [25].

Differences among GPs' and secondary-care physicians' approach to problem-oriented drug information

Significantly more GPs than secondary-care physicians requested information to support patient information (38 vs. $24 \%$ ), and consistently more GPs than secondary-care physicians used the answer to support patient information (88 vs. $70 \%$ ). This difference may reflect the difference in working procedures. The general practitioner is more often the first and only person with whom a patient is in contact through a consultation, while in the hospital the patient is usually taken care of by a team of health professionals with the nurse as the primary contact. Another difference is that in the hospital, physicians have numerous colleagues, work in more teaching-oriented settings and have daily conferences with colleagues. These differences may explain why the secondary-care physicians more often than GPs contacted the drug information centre to retrieve information for supplementary training ( 25 vs. $13 \%$ ) or for dissemination to colleagues ( 32 vs. $18 \%$ ), and why the secondary-care physicians more often than GPs used the answer for dissemination to colleagues (63 vs. 39\%). The latter is consistent with the Norwegian study, in which a higher proportion of hospital physicians than GPs discussed the answer with their colleagues (74 vs. 55\%) [15].

Secondary-care physicians search other sources more often than GPs (81 vs. 67\%) and more often search more than one source before contacting the centre. Further, secondary-care physicians used internet sources (28 vs. $14 \%)$ and scientific papers (25 vs. $7 \%$ ) more often than GPs. This corresponds to the fact that GPs more often than secondary-care physicians stated that lack of skills in searching ( 33 vs. $18 \%$ ) and evaluating the literature (18 vs. $7 \%$ ) were the motives for enquiry. Our findings may reflect that specialists are better trained in searching and EBM as they need the Internet for access to cutting-edge research. This is in accordance with an American study, which showed that more specialists than GPs use the Internet for literature search and accessing online journals for a specific topic [26]. Another weighty reason for lower use of Internet sources is that GPs work outside the library systems that provide high-quality online information to hospital-based clinicians.

\section{Limitation of the study}

A limitation of this study is that the participating physicians may not be representative of the general population of physicians. The physicians who contacted the Drug Information Centre might be more motivated for change in clinical practice than physicians who do not use our service. Instead, this study can be seen as a head-tohead study among the different users of our service. Practical and ethical reasons limit the use of classical randomised methods to assess the impact of POD, and without a control group we can not assess the number of questions that would have remained unanswered if POD was not accessible. In a pilot study on an evidence-based answering service, the physicians reported that without the service one-third of the questions would not have been pursued [20]. 
A questionnaire is problematic as it relies on the recall of the respondent and the interpretation of the question posed. Another weakness is that we only have indirect evidence of adherence to our information. The physicians were only asked how they intended to use the information. We did not investigate whether the use of the information was transformed to action, or whether it had any effects on the patient level or on a population of patients. The same is true for the use of the answers in a broader sense. Further research is needed to clarify whether POD results in a better health outcome and how this strategy compares with other possible methods of increasing access to evidence. It has been documented that physicians tend to over-report their use of journals and textbooks and underreport their reliance on colleagues and experts [27]. This may have biased our results towards a higher use of written information seeking.

We did not investigate the economic impact of our service. Cost-effective analyses of POD are methodologically difficult as the output is complex, covering a wide range of diseases, adverse reactions and patient circumstances, and there are difficulties in converting change in health into financial value [17]. The evidence of the economic impact is therefore limited and has only been evaluated in two studies [28, 29]. The methodologically best performed study investigated the economic impact of patient-specific answers over a 6-week period in 1999. Seventy-seven of 570 answers had assessable potential savings which were estimated to be $\$ 195,000$ [29].

\section{Conclusion}

Problem-oriented drug information represents a useful source for acquiring evidence-based drug information by physicians. The information is highly valued by the users and leads to reported change in clinical practice. GPs and secondary-care physicians have different preferences for POD. Compared to GPs, secondary-care physicians more often use the information for dissemination to colleagues while GPs more often use the answer to support patient information. The service is used to overcome barriers to practicing EBM such as lack of time and skills for searching and appraising the literature. Only a minor portion of the physicians use EBM sources before contacting the Drug Information Centre, whereas traditional sources such as the Drug Reference and consulting a colleague are preferred. The information was reported to have an impact on the clinical practice in the specific patient, but the results indicate that it also affects clinical practice in a broader sense for future patients and through dissemination to colleagues.

Acknowledgements The qualitative interviews reported herein form part of a dissertation by Inger Stenstrøm Rasmussen for the M.Sc. degree (Master of Health Science). The authors wish to thank Henrik
Horneberg for proofreading; Helle Nielsen, Susanne Moland and Thomas S. Christensen for technical assistance; and Dorthe Dideriksen and Kim Brøsen for carefully reading the manuscript.

\section{References}

1. Davies K (2007) The information-seeking behaviour of doctors: a review of the evidence. Health Info Libr J 24:78-94

2. Boissel JP, Amsallem E, Cucherat M et al (2004) Bridging the gap between therapeutic research results and physician prescribing decisions: knowledge transfer, a prerequisite to knowledge translation. Eur J Clin Pharmacol 60:609-616

3. Coumou HC, Meijman FJ (2006) How do primary care physicians seek answers to clinical questions? A literature review. J Med Libr Assoc 94:55-60

4. Shuval K, Shachak A, Linn S et al (2007) The impact of an evidence-based medicine educational intervention on primary care physicians: a qualitative study. J Gen Intern Med 22:327-331

5. McColl A, Smith H, White P et al (1998) General practitioner's perceptions of the route to evidence based medicine: a questionnaire survey. BMJ 316:361-365

6. Dawes M, Sampson U (2003) Knowledge management in clinical practice: a systematic review of information seeking behavior in physicians. Int J Med Inform 71:9-15

7. Oliveri RS, Gluud C, Wille-Jorgensen PA (2004) Hospital doctors' self-rated skills in and use of evidence-based medicine - a questionnaire survey. J Eval Clin Pract 10:219-226

8. Alper BS, White DS, Ge B (2005) Physicians answer more clinical questions and change clinical decisions more often with synthesized evidence: a randomized trial in primary care. Ann Fam Med 3:507-513

9. Patel MR, Schardt CM, Sanders LL et al (2006) Randomized trial for answers to clinical questions: evaluating a pre-appraised versus a MEDLINE search protocol. J Med Libr Assoc 94:382-387

10. Koonce TY, Giuse NB, Todd P (2004) Evidence-based databases versus primary medical literature: an in-house investigation on their optimal use. J Med Libr Assoc 92:407-411

11. Ely JW, Osheroff JA, Ebell MH et al (2002) Obstacles to answering doctors' questions about patient care with evidence: qualitative study. BMJ 324:710

12. Ohman B, Lyrvall HS, Tornqvist E et al (1992) Clinical pharmacology and the provision of drug information. Eur J Clin Pharmacol 42:563-567

13. Follath F, Meier C, Grimm E (1990) Computer-assisted drug information. Schweiz Med Wochenschr 120:1845-1848

14. Hedegaard U, Damkier P (2004) Clinical-pharmacological counseling in Odense, 1997-2003. Ugeskr Laeger 166:4030-4032

15. Schjott J, Pomp E, Gedde-Dahl A (2002) Quality and impact of problem-oriented drug information: a method to change clinical practice among physicians? Eur J Clin Pharmacol 57:897-902

16. Lyrvall HS (1994) The impact and use of problem-oriented drug information directed toward health staff. PhD Thesis, Department of Clinical Pharmacology, Karolinska Institute, Huddinge University Hospital

17. Hands D, Stephens M, Brown D (2002) A systematic review of the clinical and economic impact of drug information services on patient outcome. Pharm World Sci 24:132-138

18. Verhoeven AA, Schuling J (2004) Effect of an evidence-based answering service on GPs and their patients: a pilot study. Health Info Libr J 21(Suppl 2):27-35

19. Brassey J, Elwyn G, Price C et al (2001) Just in time information for clinicians: a questionnaire evaluation of the ATTRACT project. BMJ 322:529-530 
20. Swinglehurst DA, Pierce M, Fuller JC (2001) A clinical informaticist to support primary care decision making. Qual Health Care 10:245-249

21. Hayward JA, Wearne SM, Middleton PF et al (1999) Providing evidence-based answers to clinical questions. A pilot information service for general practitioners. Med J Aust 171:547-550

22. Schilling LM, Steiner JF, Lundahl K et al (2005) Residents' patient-specific clinical questions: opportunities for evidencebased learning. Acad Med 80:51-56

23. Stark R, Helenius IM, Schimming LM et al (2007) Real-time EBM: from bed board to keyboard and back. J Gen Intern Med 22:1656-1660

24. Van DD, Aertgeerts B, Hannes K et al (2007) Online on-the-spot searching increases use of evidence during consultations in family practice. Patient Educ Couns 68:61-65
25. Waldorff FB, Hermann C (2004) Rational decision making for the general practitioner: the effect of courses in Internet-based searches. Ugeskr Laeger 166:2054-2057

26. Bennett NL, Casebeer LL, Kristofco R et al (2005) Family physicians' information seeking behaviors: a survey comparison with other specialties. BMC Med Inf Decis Making 5:9

27. Covell DG, Uman GC, Manning PR (1985) Information needs in office practice: are they being met? Ann Intern Med 103:596599

28. Lyrvall HS, Nordin C, Jonsson E et al (1993) Potential savings of consulting a drug information center. Ann Pharmacother 27:1540

29. Kinky DE, Erush SC, Laskin MS et al (1999) Economic impact of a drug information service. Ann Pharmacother 33:11-16 